\title{
Correlation between Peripapillary Retinal nerve Fiber Layer Thickness and Optic Disc Parameters in Glaucoma Patients using Optical Coherence Tomography
}

\author{
A.M.Elmaghrabi, M.T.Hegazy, A.E.Daifalla and M.A.Elsayed \\ Ophthalmology Dept, Faculty of Medicine, Benha Univ., Benha, Egypt \\ E-Mail:ahmed2356@gmail.com
}

\begin{abstract}
To investigate the correlation between optic disc parameters (disc area and vertical cup disc ratio) and peripapillary retinal nerve fiber layer thickness and its value in evaluating glaucoma cases using optical coherence tomography.this study included 35 eyes of 20 patients, 9 males and 11 females. 17 eyes as glaucoma cases and 18 control eyes (age: $51.8 \pm 10.85$ years old) were recruited at ophthalmology department at Benha university hospital. Finish ophthalmic assessment, visual field Also oct optic nerve imaging were completed In the examination unit of the division. Circle range (DA) qualities $(\mathrm{M} \pm \mathrm{SD})$ were 2. $31 \pm 0.34$ Furthermore 2. $69 \pm 0.51$ for cases Also control separately (P value: 0.016$)$. VCDR values $(\mathrm{M} \pm \mathrm{SD}$ ) were $0.67 \pm 0.16$ What's more $0.62 \pm 0.14$ to instances What's more control individually ( $\mathrm{p}$ value: 0 . 28). Da indicate main noteworthy connection should nasal PPRNFL thickness same time VCDR show main critical negative correspondence on Normal PPRNFL thickness. There may be critical sure relationship between VCDR What's more da. Roc bend Investigation trying legitimacy of da Also VCDR to foresee glaucoma demonstrate helter skelter affectability (82. 4\%) Also low specificity (61.1\%) to da (p esteem 0. 009) Also low affectability (58. 8\%) Also low specificity (44. 4\%) for VCDR (p worth 0.85 ). VCDR might be a uncaring technique for assessing alternately screening glaucomatous practical harm On POAG alternately classifying its seriousness. Circle zone altogether influences VCDR Also might need a part done foreseeing POAG instances.
\end{abstract}

Keywords: PPRNFL, Peripapillary Retinal nerve fiber layer, VCDR, Disc area, POAG, Optical coherence tomography (OCT).

\section{Introduction}

Glaucoma may be depicted Concerning illustration a optic neuropathy for copartnered visual work passing. Despite raised intraocular weight (IOP) may be those A large portion significant danger factors, it doesn't bring a part in the definition of the sickness [1] . Those planet wellbeing association (WHO) assessed that glaucoma is the second commonest reason for visual deficiency overall [2]. A glaucoma suspect is characterized as a mature person who need no less than a standout amongst the taking after discoveries clinched alongside no less than one eye: an optic nerve or nerve fiber layer (NFL) abandon sugi glaucoma (enlarged cup-disc proportion (CDR), deviated CDR, notching or narrowing of the neuro-retinal rim, An circle discharge or suspicious modification in the NFL), a visual field abnormality reliable for glaucoma What's more a raised IOP more amazing over $21 \mathrm{~mm} \mathrm{hg}$. Usually, Assuming that two or A greater amount of these discoveries are present, those analysis for grade open point glaucoma (POAG) may be supported, particularly in the vicinity for different danger figures for example, such that age, a family history for glaucoma and the dark race Also no different optional makes. Those finding of a glaucoma suspect What's more POAG may be Additionally subject to an ordinary open point with respect to Gonioscopy [3]. A magnified, preferably stereoscopic, examination of the optic circle utilizing a 90 diopter (D) lens alternately An contact lens with the opening light may be the Perfect system for looking at these structures [4]. Verthandi prolongation of the optic glass will be An trademark characteristic of glaucomatous optic neuropathy. The verthandi container should circle proportion (VCDR) may be An simple, strong pointer from claiming glaucomatous passing of the neuroretinal edge [5]. However huge numbers factors similar to histological structure of nerve axons What's more lamina cribrosa influence the circle span Furthermore CDR [6]. Also, the capacity of CDR to recognize glaucoma will be set because of those totally variability about CDRs in the ordinary populace. Such variability may be explained, in any event clinched alongside part, by the critical association the middle of those CDR and the span of the optic circle (OD) $[7,8]$ in An investigation investigating relationship between CDR Also retinal ganglion Mobile (RGC) reasoned that appraisal for CDR will be an uncaring strategy to assessment from claiming progressive neural misfortunes clinched alongside glaucoma [9]. Verthandi glass circle proportion (VCDR) is also influenced Eventually Tom's perusing optic circle span Furthermore pivotal period of the eye. The sole utilization of VCDR percentile curtailed offs to characterizing glaucoma cases to populace surveys obliges further acceptance [10].

\section{Aim of the study}

To investigate the correlation between optic disc parameters (disc area and vertical cup disc ratio) and peripapillary retinal nerve fiber layer thickness and its value in evaluating glaucoma cases using optical coherence tomography.

\section{Subjects and metods}

This Hospital-based cross sectional observational contemplate incorporated successive allotment for glaucoma suspects and grade open point glaucoma Concerning illustration they exhibited of the particular eye focal point during Benha school doctor's facility.

20 members were recruited and educated assent might have been made from the greater part. Incorporation criteria were glaucoma suspects with open angles on 
gonioscopy (grades iii What's more iv Shaffer's' evaluating system), officially diagnosed patients with essential open point glaucoma or late analysis about POAG. Prohibition criteria were point Conclusion glaucoma, auxiliary glaucoma, uncooperative patients Also agdistis beneath 18 .

Members were picked starting with those all ophthalmology facility because about suspicious discs or raised IOP then afterward medicines to other visual states. Those best remedied visual sharpness might have been measured. Participant's pupils were widened utilizing tropicamide $1 \%$ after intra-ocular weight estimation Eventually Tom's perusing Goldmann applanation tonometry What's more gonioscopic examination. A opening light binocular backhanded ophthalmoscopy utilizing +78D / $90 \mathrm{~d}$ (Volks) lens might have been used to analyze those optic nerve mind and retinal nerve fiber layer. Members for shallow fragment hemorrhage, central misfortune for neuro-retinal edge (notching), summed up reduction from claiming neuroretinal edge (VCDR $\geq 0$. 5), cup-disc proportion asymmetry $(\geq 0.2)$ alternately misfortune from claiming retinal nerve fibers were permitted should proceed for the contemplate. Likewise members whose optic nerve leader and nerve fibers seemed typical However required IOP more amazing over $21 \mathrm{mmhg}$ were also incorporated.

Visual field might have been completed on every last bit cases utilizing Carl Zeiss ag robotized Humphrey perimeter, model $745 \mathrm{i}$, produced to Germany, utilizing sita system and 24-2 degree trying.

Oct were finished should constantly on ponder Assemblies utilizing sd (spectral domain) Topcon $3 \mathrm{~d}$ oct 2000, settled on in Japan, 2014. Optic circle topolatry
Also peripapillary retinal nerve fiber layer need aid imaged utilizing $3 \mathrm{~d}$ cubic of $(6 \mathrm{mmX} 6 \mathrm{~mm})$ range. Circle zone will be distinguished Toward identification of the RPE edges (disc identification points) What's more An reference surface interfacing these focuses will be made In this way circle range might make computed. VCDR will be measured Concerning illustration those proportion from claiming tallness of the rectangle circumscribing container range against the stature of the rectangle circumscribing the circle zone. PPRNFL is imaged Also parts are distinguished done clock hours alternately degrees. Predominant division is 45:135degree Furthermore As needs be every segment speaks to 90 level.

\section{Results}

The study included 35 eyes of 20 patients, 9 males and 11 females, classified as 17 eyes of glaucoma patients and 18 eyes of non-glaucoma patients. The mean age for participants was $51.8 \pm 10.85$ years old. Tables (1) and (2) show demographic data of included individuals.

Table (1) Distribution of the studied group according to personal factors.

\begin{tabular}{|c|c|c|}
\hline & \multicolumn{2}{|c|}{ The studied group (35) } \\
\hline & No & $\%$ \\
\hline \multicolumn{3}{|l|}{ Gender } \\
\hline Male & 9 & 45.0 \\
\hline Female & 11 & 55.0 \\
\hline $\begin{array}{l}\text { Age mean } \pm \mathrm{SD} \text {, } \\
\text { range }\end{array}$ & \multicolumn{2}{|c|}{$51.8 \pm 10.85,20-67$} \\
\hline
\end{tabular}

Table (2) Comparison between case and control groups according to personal factors.

\begin{tabular}{|c|c|c|c|c|c|c|}
\hline & \multicolumn{2}{|c|}{ Case group (9) } & \multicolumn{2}{|c|}{ Control group (11) } & \multirow[t]{2}{*}{ Statistical test } & \multirow[t]{2}{*}{$P$ value } \\
\hline & No & $\%$ & No & $\%$ & & \\
\hline \multicolumn{7}{|l|}{ Gender } \\
\hline Male & 3 & 33.3 & 6 & 54.5 & $\mathrm{FET}=0.90$ & 0.34 \\
\hline Female & 6 & 66.7 & 5 & 45.5 & & \\
\hline Age mean $\pm S$ & 55.44 & 6.64 & 48.82 & 12.91 & St $t=1.39$ & 0.18 \\
\hline
\end{tabular}

Comparison between clinical findings of cases and controls is demonstrated in table (3). IOP values was statistically significant $(\mathrm{P}$ value $<0.001)$ with the mean for cases was $24.35 \pm 8.33 \mathrm{mmHg}$ and for control was $14.22 \pm$ $2.26 \mathrm{mmHg}$. CDR was $0.57 \pm 0.18$ for cases while it was $0.56 \pm 0.14$ for controls with no statistical significance $(P$ value: 0.79 ).

The data of OCT examination are illustrated in table (4). The mean disc area was $2.31 \pm 0.34$ for cases and $2.69 \pm 0.51$ for control group and was statistically significant ( $\mathrm{P}$ value: 0.016 ). The mean vertical CDR was $0.67 \pm 0.16$ and $0.62 \pm 0.14$ for cases and control respectively without statistical significance ( $p$ value: 0.28).the mean of average PPRNFL thickness was 72.94 \pm 16.32 for cases and was $98.17 \pm 10.92$ for control with statistical significance $(\mid \mathrm{p}$ value $<0.001)$. inferior sector of PPRNFL was the thickest in case and control group with mean thickness of $88.35 \pm 33.86$ and BCVA: Best corrected visual acuity. IOP: intraocular pressure. CDR: cup disc ratio. NAD: no abnormality detected. Ns: nuclear sclerosis. N1: nuclear cataract grade 1. RRR: round regular and reactive. PPRNFL: peripapillary retinal nerve fibre layer.

$118.5 \pm 13.51$ for case and control respectively and was statistically significant( $\mathrm{p}$ value 0.001). Superior PPRNFL mean thickness was 81.06 \pm 28.47 and $119.5 \pm 15.94$ for cases and control respectively with statistical significance ( $\mathrm{p}$ value $<0.001$ ). Nasal PPRNFL mean thickness was $63.76 \pm 15.15$ and $86.83 \pm 16.27$ for cases and control respectively with statistical significance ( $\mathrm{p}$ value $<0.001$ ). Temporal PPRNFL mean thickness was $58.24 \pm 14.7$ and $68.17 \pm 13.68$ for cases and control respectively with the least statistical significance ( $\mathrm{p}$ value 0.046). 
Visual field examination was done and revealed arcuate scotoma as the most common finding (41.2\%).
Results of visual field examination are presented in table (5).

Table (3) comparison between cases and control, clinical data.

\begin{tabular}{|c|c|c|c|c|c|c|}
\hline & \multicolumn{2}{|c|}{ Case group (17 eye) } & \multicolumn{2}{|c|}{ Control group (18 eye) } & \multirow{2}{*}{$\begin{array}{c}\text { Statistical } \\
\text { test }(\text { st t test) }\end{array}$} & \multirow[t]{2}{*}{ P value } \\
\hline & Mean & $\pm \mathrm{SD}$ & Mean & $\pm \mathrm{SD}$ & & \\
\hline BCVA & 0.43 & 0.29 & 0.65 & 0.22 & 2.57 & $0.015^{*}$ \\
\hline Median (IR) & \multicolumn{2}{|c|}{$0.50(0.18-0.55)$} & \multicolumn{2}{|c|}{$0.50(0.50-0.90)$} & $\mathrm{MW}=1.97$ & $0.049 *$ \\
\hline IOP & 24.35 & 8.33 & 14.22 & 2.26 & 4.97 & $<0.001 * *$ \\
\hline CDR & 0.57 & 0.18 & 0.56 & 0.14 & 0.28 & 0.79 \\
\hline \multicolumn{7}{|l|}{ Gonioscopy : } \\
\hline G2 & 2 & 11.8 & 0 & 0.0 & $\mathrm{FET}=2.25$ & 0.23 \\
\hline G3 & 15 & 88.2 & 18 & 100 & & \\
\hline \multicolumn{7}{|l|}{ Lens : } \\
\hline NAD & 4 & 23.5 & 7 & 38.9 & $\mathrm{FET}=4.88$ & 0.30 \\
\hline Ns & 9 & 52.9 & 6 & 33.3 & & \\
\hline N1 & 2 & 11.8 & 3 & 16.7 & & \\
\hline PS & 2 & 11.8 & 0 & 0.0 & & \\
\hline PSCC & 0 & 0.0 & 2 & 11.1 & & \\
\hline \multicolumn{7}{|l|}{ Pupil : } \\
\hline RRR & 14 & 82.4 & 18 & 100 & $\mathrm{FET}=1.59$ & 0.104 \\
\hline Sluggish & 3 & 17.6 & 0 & 0.0 & & \\
\hline \multicolumn{7}{|l|}{ Fundus finding : } \\
\hline PPRNFL Defect & 4 & 23.5 & 0 & 0.0 & $\mathrm{FET}=6.51$ & $0.008 * *$ \\
\hline Myopic crescent & 2 & 11.8 & 0 & 0.0 & & \\
\hline No abnormalities & 11 & 64.7 & 18 & 100 & & \\
\hline
\end{tabular}

Table (4) comparison between cases and control, OCT finding .

\begin{tabular}{|c|c|c|c|c|c|c|}
\hline & \multicolumn{2}{|c|}{ Case group (17 eye) } & \multicolumn{2}{|c|}{ Control group (18 eye) } & \multirow{2}{*}{$\begin{array}{r}\text { Statistical test } \\
\text { (st t test) }\end{array}$} & \multirow[t]{2}{*}{$P$ value } \\
\hline & Mean & \pm SD & Mean & $\pm \mathrm{SD}$ & & \\
\hline Disc area & 2.31 & 0.34 & 2.69 & 0.51 & 2.54 & $0.016^{*}$ \\
\hline Cup area & 1.01 & 0.26 & 1.13 & 0.54 & 0.84 & 0.41 \\
\hline Vertical CDR & 0.67 & 0.16 & 0.62 & 0.14 & 1.09 & 0.28 \\
\hline Inferior PPRNFL & 88.35 & 33.86 & 118.5 & 13.51 & 3.5 & $0.001 * *$ \\
\hline $\begin{array}{l}\text { Superior } \\
\text { PPRNFL }\end{array}$ & 81.06 & 28.47 & 119.5 & 15.94 & 4.97 & $<0.001 * *$ \\
\hline Nasal PPRNFL & 63.76 & 15.15 & 86.83 & 16.27 & 4.34 & $<0.001 * *$ \\
\hline $\begin{array}{l}\text { Temporal } \\
\text { PPRNFL }\end{array}$ & 58.24 & 14.7 & 68.17 & 13.68 & 2.07 & $0.046^{*}$ \\
\hline Average thickness & 72.94 & 16.32 & 98.17 & 10.92 & 5.4 & $<0.001 * *$ \\
\hline
\end{tabular}

Table (5) visual field finding of the case group.

\begin{tabular}{lll}
\hline & \multicolumn{2}{l}{ Case group (17 eye) } \\
\cline { 2 - 3 } & No & \% \\
\hline Arcuate scotoma & 7 & 41.2 \\
Borderline & 2 & 11.8 \\
Para central & 1 & 5.9 \\
scotoma & 1 & 5.9 \\
Tubular field & 2 & 11.8 \\
Nasal step & 4 & 23.5 \\
Insignificant & & \\
\hline
\end{tabular}

Correlation between optic disc parameters, clinical and OCT variables for case and control groups was done using r-test. Correlation is considered statistically significant when $\mathrm{p}$ value is less than 0.05 .
In the case group, Disc area was inversely correlated to BCVA, IOP and VCDR with only statistical significance for VCDR. Disc area was directly correlated to average PPRNFL thickness and to all sectors of 
PPRNFL except temporal one. It is only statistically significant to nasal sector. Correlation between disc area and other variables in the case group is shown in table (6).

Table (6) correlation between disc area and clinical and OCT variables for case group.

\begin{tabular}{lcl}
\hline Case group (17) & \multicolumn{2}{c}{ Disc area } \\
\cline { 2 - 3 } & $\begin{array}{c}\text { Statistical test } \\
(\mathbf{r} \text { test) }\end{array}$ & P value \\
\hline BCVA & -0.40 & 0.12 \\
IOP & -0.24 & 0.37 \\
Cup area & 0.23 & 0.38 \\
Vertical CDR & -0.50 & $0.043^{*}$ \\
Inferior PPRNFL & 0.34 & 0.18 \\
Superior PPRNFL & 0.45 & 0.068 \\
Nasal PPRNFL & 0.68 & $0.003^{* *}$ \\
Temporal PPRNF & -0.29 & 0.26 \\
Average thickness & 0.46 & 0.064 \\
\hline
\end{tabular}

Results of correlating VCDR measured by OCT to clinical data and other OCT variables are presented in table (7). VCDR is inversely correlated to BCVA and IOP without statistical significance. It is directly correlated to $\mathrm{CDR}$ assessed clinically with strong statistical significance. VCDR was directly correlated to cup area without statistical significance. VCDR was inversely correlated to average PPRNFL and all sector thickness but only statistically significant for the average thickness.

Table (7) correlation between VCDR measured by OCT to clinical data and other OCT variables in case group.

\begin{tabular}{lcc}
\hline Case group (17) & \multicolumn{2}{c}{ Vertical CDR } \\
\cline { 2 - 3 } & $\begin{array}{c}\text { Statistical test } \\
(\mathbf{r} \text { test) }\end{array}$ & P value \\
\hline BCVA & -0.09 & 0.74 \\
IOP & -0.053 & 0.84 \\
CDR & 0.78 & $<0.001^{* *}$ \\
Cup area & 0.43 & 0.083 \\
Inferior PPRNFL & -0.41 & 0.10 \\
Superior PPRNFL & -0.38 & 0.13 \\
Nasal PPRNFL & -0.46 & 0.06 \\
Temporal PPRNFL & -0.21 & 0.41 \\
Average thickness & -0.56 & $0.021^{*}$ \\
\hline
\end{tabular}

In the control group, table (8) shows that disc area is inversely correlated to BCVA with no statistical significance. It is directly correlated to cup area, VCDR, average PPRNFL and all other sector thickness with only statistical significance to average and temporal thickness.

Table (8) correlation between disc area and clinical \& OCT variables in control group.

\begin{tabular}{lcc}
\hline Control group & \multicolumn{2}{c}{ Disc area } \\
\cline { 2 - 3 } & $\begin{array}{c}\text { Statistical test } \\
\text { (r test) }\end{array}$ & P value \\
\hline BCVA & -0.13 & 0.60 \\
IOP & 0.14 & 0.58 \\
Cup area & 0.60 & $0.009^{*}$ \\
Vertical CDR & 0.13 & 0.60 \\
Inferior PPRNFL & 0.24 & 0.35 \\
Superior & 0.36 & 0.15 \\
PPRNFL & & \\
Nasal PPRNFL & 0.25 & 0.31 \\
Temporal & 0.54 & $0.021^{*}$ \\
PPRNFL & & \\
Average thickness & 0.47 & $0.05^{*}$ \\
\hline
\end{tabular}


Table (9) presents correlation between VCDR measured by OCT to clinical data and other OCT variables in control group. VCDR was directly correlated to BCVA, IOP, CDR and cup area but only statistically significant for $\mathrm{CDR}$ and cup area. It was inversely correlated to PPRNFL thickness, average and all sectors with no statistical significance.
To test validity of optic disc parameters (disc area and VCDR) in glaucoma prediction, ROC curves and chi square test (x2) statistical test was done.

Table (10) and Fig (1) show validity of disc area in prediction of glaucoma. A disc area more than $2.62 \mathrm{~m} 2$ (cut-off point) can predict development of glaucoma with statistical significance $(95 \%$ CI $0.712(0.535-0.89), \mathrm{p}$ value 0.009$)$ with high sensitivity $(82.4 \%)$ and low specificity $(61.1 \%)$.

Table (9) correlation between VCDR measured by OCT to clinical data and other OCT variables in control group.

\begin{tabular}{lcc}
\hline Control group (18) & \multicolumn{2}{c}{ Vertical CDR } \\
\cline { 2 - 3 } & Statistical test $(\mathbf{r}$ test) & P value \\
\hline BCVA & 0.28 & 0.26 \\
IOP & 0.05 & 0.84 \\
CDR & 0.97 & $<0.001^{* *}$ \\
Cup area & 0.82 & $<0.001^{* *}$ \\
Inferior PPRNFL & -0.08 & 0.75 \\
Superior PPRNFL & -0.45 & 0.06 \\
Nasal PPRNFL & -0.35 & 0.16 \\
Temporal PPRNFL & -0.17 & 0.51 \\
Average thickness & -0.36 & 0.14 \\
\hline
\end{tabular}

Table (10) Validity of disc area in prediction of glaucoma.

\begin{tabular}{|c|c|c|c|c|c|c|}
\hline & \multicolumn{2}{|c|}{ Case group (17 eye) } & \multicolumn{2}{|c|}{ Control group (18 eye) } & \multirow[t]{2}{*}{ Statistical test $\left(\mathrm{x}^{2}\right)$} & \multirow[t]{2}{*}{$P$ value } \\
\hline & No & $\%$ & No & $\%$ & & \\
\hline$\leq 2.62$ & 14 & 82.4 & 7 & 38.9 & 6.88 & $0.009 * *$ \\
\hline$>2.62$ & 3 & 17.6 & 11 & 61.1 & & \\
\hline AUC $(95 \%$ CI $)$ & & & & $535-0.89$ & & \\
\hline Cut-off point & & & & $2 \mathrm{~m} 2$ & & \\
\hline Sensitivity & & & & $.4 \%$ & & \\
\hline Specificity & & & & $.1 \%$ & & \\
\hline PPV & & & & $.7 \%$ & & \\
\hline NPV & & & & $6 \%$ & & \\
\hline Accuracy & & & & $1.4 \%$ & & \\
\hline
\end{tabular}

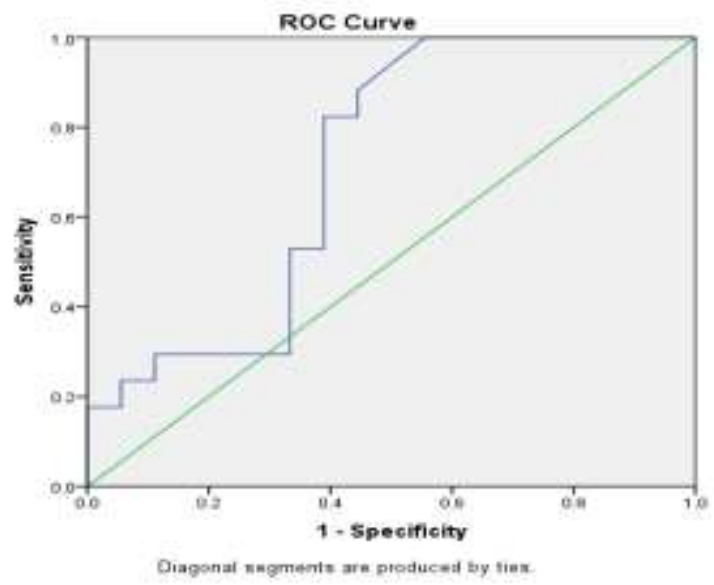

Fig (1) Validity of disc area in prediction of glaucoma.

Table (11) and Fig (2) show results of testing validity of VCDR to predict glaucoma development. It shows that
VCDR more than 0.63 (cut-off point) can be associated with glaucoma development but with no statistical 
significant (95\% CI 0.585 (0.393-0.777), p value 0.85). it

$(44.4 \%)$. has also low sensitivity $(58.8 \%)$ and low specificity Table (11) Validity of VCDR in prediction of glaucoma.

\begin{tabular}{|c|c|c|c|c|c|c|}
\hline & \multicolumn{2}{|c|}{ Case group (17 eye) } & \multicolumn{2}{|c|}{ Control group (18 eye) } & \multirow[t]{2}{*}{ Statistical test $\left(\mathrm{x}^{2}\right)$} & \multirow[t]{2}{*}{$P$ value } \\
\hline & No & $\%$ & No & $\%$ & & \\
\hline$\geq 0.63$ & 10 & 58.8 & 10 & 55.6 & 0.04 & 0.85 \\
\hline$<0.63$ & 7 & 41.2 & 8 & 44.4 & & \\
\hline $\operatorname{AUC}(95 \% \mathrm{CI})$ & & & & $\left(0.393-0.77^{\prime}\right.$ & & \\
\hline Cut-off point & & & & $0.63 \%$ & & \\
\hline Sensitivity & & & & $58.8 \%$ & & \\
\hline Specificity & & & & $44.4 \%$ & & \\
\hline PPV & & & & $50.0 \%$ & & \\
\hline NPV & & & & $53.3 \%$ & & \\
\hline Accuracy & & & & $51.4 \%$ & & \\
\hline
\end{tabular}

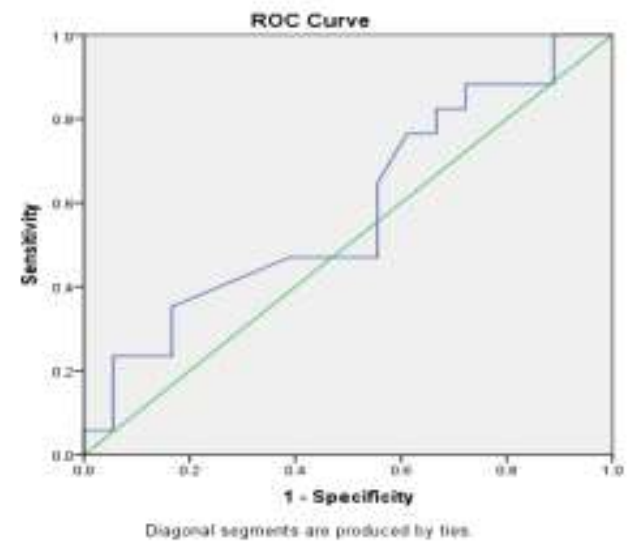

Fig (2) Validity of VCDR in prediction of glaucoma.

To test impact of increasing VCDR measured by OCT on the thickness of PPRNFL in case and control group, VCDR is categorized into 3 categories as shown in tables 12 and 13. Category 1 includes VCDR less than 0.5 . Category 2 includes VCDR 0.5:0.7. Category 3 includes VCDR more than 0.7 .

Table (12) shows effect of increasing VCDR on PPRNFL thickness in case group. It shows that PPRNFL thickness, average and all sectors, decreases by transitioning from category 1 to 2 to 3 but with no statistical significance. Inferior and superior PPRNFL are the most affected especially when transition from category 1 to 2 . Inferior PPRNFL shows decrease by mean percent of $35.05 \%$ while superior PPRNFL thickness shows decrease by mean percent of $35.98 \%$ from category 1 to 2 . Transition from category 2 to 3 was associated with less decrease in PPRNFL thickness.

Table (12) Effect of increasing VCDR on PPRNFL thickness in case group.

\begin{tabular}{|c|c|c|c|c|c|c|c|c|}
\hline \multirow{2}{*}{$\begin{array}{l}\text { Vertical } \\
\text { C/D }\end{array}$} & \multicolumn{2}{|c|}{ Cat I $(<0.5)$} & \multicolumn{2}{|c|}{ Cat II (0.5-0.7) } & \multicolumn{2}{|c|}{ Cat III (>0.7) } & \multirow{2}{*}{$\begin{array}{c}\text { Statistical test } \\
\text { (ANOVA) }\end{array}$} & \multirow[t]{2}{*}{$P$ value } \\
\hline & Mean & $\pm \mathrm{SD}$ & Mean & $\pm \mathrm{SD}$ & Mean & $\pm \mathbf{S D}$ & & \\
\hline Inferior & 127.5 & 33.23 & 82.8 & 33.27 & 83.8 & 30.83 & 1.64 & 0.23 \\
\hline Superior & 119.5 & 7.78 & 76.5 & 24.22 & 74.8 & 32.67 & 2.45 & 0.12 \\
\hline Nasal & 73.5 & 20.51 & 66.7 & 13.12 & 54.0 & 15.41 & 1.81 & 0.20 \\
\hline Temporal & 55.5 & 3.54 & 62.2 & 17.28 & 51.4 & 9.37 & 0.93 & 0.42 \\
\hline $\begin{array}{l}\text { Average } \\
\text { thickness }\end{array}$ & 93.5 & 10.61 & 72.5 & 12.94 & 65.6 & 19.51 & 2.49 & 0.12 \\
\hline
\end{tabular}

Table (13) shows effect of increasing VCDR on PPRNFL thickness in control group. It shows no statistical significance except for differences of nasal PPRNFL thickness. In this study, VCDR category 1 (less than 0.5$)$ represents $16.66 \%$ of control group. VCDR of category $2(0.5: 0.7)$ represent $66.66 \%$ of normal control eyes with normal PPRNFL thickness. Category 3 (VCDR more than 0.7 ) represents $16.66 \%$ with normal PPRNFL thickness. 
Table (13) Effect of increasing VCDR on PPRNFL thickness in control group.

\begin{tabular}{|c|c|c|c|c|c|c|c|c|}
\hline \multirow[t]{2}{*}{$\begin{array}{l}\text { Vertical } \\
\text { C/D }\end{array}$} & \multicolumn{2}{|c|}{ Cat I $(<0.5)(3)$} & \multicolumn{2}{|c|}{$\begin{array}{c}\text { Cat II (0.5-0.7) } \\
(12)\end{array}$} & \multicolumn{2}{|c|}{$\begin{array}{c}\text { Cat III (>0.7) } \\
\text { (3) }\end{array}$} & \multirow[t]{2}{*}{$\begin{array}{l}\text { Statistical test } \\
\text { (ANOVA) }\end{array}$} & \multirow[t]{2}{*}{$P$ value } \\
\hline & Mean & \pm SD & Mean & \pm SD & Mean & \pm SD & & \\
\hline Inferior & 122.33 & 18.77 & 115.75 & 11.69 & 125.67 & 17.39 & 0.77 & 0.48 \\
\hline Superior & 136.0 & 9.54 & 113.92 & 14.21 & 125.33 & 17.67 & 3.2 & 0.069 \\
\hline Nasal & 108.33 & 19.86 & $82.33 \mathrm{a}$ & 12.52 & $83.33 \mathrm{a}$ & 12.66 & 4.41 & $0.031 *$ \\
\hline Temporal & 72.0 & 10.0 & 66.83 & 14.36 & 69.67 & 17.93 & 0.17 & 0.84 \\
\hline $\begin{array}{l}\text { Average } \\
\text { Thickness }\end{array}$ & 109.33 & 9.61 & 94.67 & 9.39 & 101.0 & 12.76 & 2.76 & 0.095 \\
\hline
\end{tabular}

(a):significant with category I

\section{Discussion}

Optic nerve mind What's more PPRNFL thickness progressions would a standout amongst those paramount criteria should diagnose Furthermore catch up POAG. (3) Normal and territorial PPRNFL of the control one assembly need aid comparable to that discovered to different investigations in Alasil t et al [11]. Normal and territorial PPRNFL of the case one assembly need aid underneath ordinary values and were statistically noteworthy.

VCDR will be a paramount clinical device continuously The majority influenced over glaucoma patients because of its histological variety On predominant and subpar poles of the circle What's more more influenced Toward mechanical Furthermore vascular harm [12]. Done our study, intend VCDR was0. $67 \pm 0$. 16 Also 0. $62 \pm 0.14$ to cases Also control separately without measurable hugeness ( $p$ value: 0.28 ). Imply VCDR for control gathering will be higher over recorded clinched alongside different investigations. Andres segovia et al accounted intend VCDR should be 0. 45 for ordinary individuals What's more $\mathrm{j} g$ Crowston et al accounted for it on be 0.43 and accounted for measurable essentialness At contrasted with that about glaucomatous eyes [9, 10]. This might be attributed should little amount from claiming our test Furthermore needs All the more test size on provide for additional dependable effects.

Imply VCDR to instance one assembly might have been close to qualities accounted for in past investigations like andres segovia et al (0. 62) What's more Willekens $\mathrm{k}$ et al $(0.69)$. $(9,13)$. VCDR will be recognized will be a great device around to diagnose glaucomatous transforms since 1960 Eventually Tom's perusing Snydacker d et al Also underpinned via late investigations similar to George ACF et al, thomas $r$ et al and Willekens $\mathrm{k}$ et al $[3,4,13,14]$. Our investigation comes about uncovered negative correspondence between VCDR Furthermore PPRNFL thickness that might have been main statistically noteworthy for those Normal PPRNFL thickness. To the control group, this relationship might have been inconsequential statistically but with nasal division which might have been specifically associated with VCDR.

Andres segovia $\mathrm{j}$ et al examined the relationship of VCDR will RGC layer Furthermore found that VCDR will be an uncaring apparatus should assess glaucoma progression. (9) Also, j g Crowston et al prescribed further acceptance of VCDR to utilize it for analysis from claiming glaucoma. (10) same time temporary PJ et al accounted for that VCDR may be a great variable to diagnose and screen glaucoma situations [5]. those discuss regarding the part of VCDR done analysis Furthermore screening glaucoma cases might be expected on totally variability of the VCDR in typical number What's more its love by those optic circle measure $[7,8]$. Garway-Heath DF et al found huge immediate correspondence between VCDR Furthermore circle span [7]. This will be underpinned via our finding that found circle An statistically critical immediate correspondence the middle of circle zone and VCDR on account assembly (table 6).

VCDR might not reflect the harm done PPRNFL as it may be influenced mechanically Toward the helter skelter IOP and the histological variability from claiming lamina cribrosa structure that might assume a part Previously, VCDR variability Around patients [12]. Acomparable finding happens in instances with intrinsic glaucoma for which an expansive glass is noted with secondary IOP that might profit will typical after IOP control [15]. Additionally those microvasculature of the optic circle What's more territorial blood supply about lamina cribrosa and the circle might assume a part to glaucomatous harm Also its natural inclination on particular territories in the circle [16, 17]. Clinched alongside our study, legitimacy of circle zone What's more VCDR with foresee glaucoma situations might have been tried utilizing roc curves and chi square test (x2) measurable tests. In this ponder circle region demonstrate statistically noteworthy helter skelter affectability (82. $4 \%)$ Yet direct specificity (61. 1\%) looking into a premise about cut off esteem for $2.62 \mathrm{~mm} 2$. VCDR hint at non-statistically huge comes about for moderate affectability (58. 8\%) and low specificity (44. 4\%). Stuart $\mathrm{k}$ et al indicates over as much examine that circle territory Also VCDR could make useful predictors to glaucoma progression Furthermore utilitarian harm to glaucoma. (18) Larrosa JM et al contemplate legitimacy about PPRNFL Also optic circle parameters clinched alongside diagnosing and screening glaucoma Also indicate secondary sensitivity/specificity (80. 5/80. 7\%) to mediocre PPRNFL Also these qualities might have 
been $61.2 \%$ affectability Also $89.1 \%$ specificity to VCDR [19]. this outcomes would heterogeneous viewing symptomatic exactness about VCDR, circle territory and PPRNFL thickness so, it necessities further investigations should assess such parameters.

For concentrating on those impact of expanding VCDR on the PPRNFL thickness in the event aggregation table (12), it reveals to that PPRNFL thickness, Normal What's more the sum sectors, declines by transitioning starting with classification 1 to 2 on 3 Anyway with no measurable noteworthiness. Subpar What's more predominant PPRNFL need aid the mossycup oak influenced particularly At move starting with classification 1 will 2 . Second rate PPRNFL reveals to diminishing Toward intend percent for $35.05 \%$ same time predominant PPRNFL thickness indicates diminish by intend percent about $35.98 \%$ starting with class 1 on 2. Move from class 2 will 3 might have been connected with lesquerella diminish Previously, PPRNFL thickness. With respect to mulling over comparable connection in the control aggregation (table 13), it demonstrates no Factual hugeness but to contrasts about nasal PPRNFL thickness. In the control group, VCDR class 1 (less over $0.5)$ speaks to $16.66 \%$ for control one assembly. VCDR from claiming class $2(0.5: 0.7)$ representable $66.66 \%$ of typical control eyes for ordinary PPRNFL thickness. Classification 3 (VCDR more than 0. 7) speaks to 16. $66 \%$ with typical PPRNFL thickness. This comes about demonstrate that seriousness arrangement for glaucoma cases contingent upon VCDR evaluation might make erroneous Also necessities that's only the tip of the iceberg assessment.

\section{Conclusion}

At those limit we could presume that appraisal for VCDR alone might be uncaring technique for assessing alternately observing glaucomatous practical harm clinched alongside POAG. VCDR might reflect just practical harm to Normal PPRNFL thickness. Circle region altogether influences VCDR and might have a part On foreseeing POAG situations. Also, VCDR is erroneous system with arrange POAG situations. Further investigations need aid required with a greater amount example span What's more fixation looking into distinctive catch up for accepting our comes about. Also, All the more vast investigations need aid necessary with test symptomatic accuracy, affectability Also specificity from claiming optic circle parameters Previously, assessing glaucoma instances.

\section{Disclosure}

Financial support: no financial support was received for submission.

Conflict of interest: the authors have no conflict of interest to declare.

\section{References}

[1] A. C. F. George , D. Jane , C. A. Girkin , Introduction to glaucoma: Terminology, epidemiology, and heredity: Basic and clinical science course, section 10, chapter 1 American Academy of Ophthalmology, Singapore. Vol. 3-7, PP.23-70,2011.

[2] S. Resnikoff , D. Pascolini , D. Etya'ale , Global data on visual impairment in the year 2002 Bull World Health Organ,vol. 82, PP.844-851, 2004.

[3] A. C. F. George , D. Jane , C. A. Girkin , OpenAngle Glaucoma: In: Basic and clinical science course, section 10, chapter 4; American Academy of Ophthalmology, Singapore. Vol. 15, pp.96-99, 2011.

[4] R. Thomas , R. S. Parikh How to assess a patient for glaucoma. Community Eye Health. vol. 19, PP.36-7, 2011.

[5] P. J. Foster ,R.Buhrmann , A. H. Quigley, The definition and classification of glaucoma in prevalence surveys. Br Ophthalmol. Vol. 86, PP.238-42, 2001.

[6] J. B. 1.Jonas ,G. S. Gusek , G. O. Naumann Optic disc, cup and neuroretinal rim size, configuration and correlations in normal eyes. Invest Ophthalmol Vis Sci. Jul. Vol. 29(7), PP.1151-8, 1998.

[7] D. F. Garway-Heath ,S. T. Ruben , A. Viswanathan ,Vertical cup/disc ratio in relation to optic disc size: its value in the assessment of the glaucoma suspect. Br J Ophthalmol. Vol. 82, PP.1118-1124, 1998.

[8] E. F. Carpel , p. F. Engstrom . The normal cup-disk ratio. Am J Ophthalmol. Vol. 91, PP.588-597, 1981.

[9] Andrew J. Tatham, Robert N. Weinreb, Linda M. Zangwill, Jeffrey M. Liebmann, Christopher A. Girkin, Felipe A. Medeiros, The Relationship Between Cup-to-Disc Ratio and Estimated Number of Retinal Ganglion Cells Invest Ophthalmol Vis Sci. May. vol. 54(5), PP.3205-3214, 2013.

[10] J. G. Crowston, C.R. Hopley, P. R. Healey, The effect of optic disc diameter on vertical cup to disc ratio percentiles in a population based cohort. The Blue Mountains Eye Study. Br. J Ophthalmol. Jun. vol. 88(6), PP.766-770, 2004.

[11]T. Alasil T, Wang K, Keane PAnalysis of normal retinal nerve fiber layer thickness by age, sex, and race using spectral domain optical coherence tomography2013 Sep. Vol. 22(7), PP.532-41, 2013.

[12]S. Xu ,D. S. Minkler : Vascularity of the human optic nerve head. Invest Ophthalmol Vis Sci (suppl). Vol. 25, PP.224, 1984.

[13] K. Willekens ,S. Bataillie, p. Sarens, Funduscopic versus HRT III Confocal Scanner Vertical Cup-Disc Ratio Assessment in Normal Tension and Primary Open Angle Glaucoma (The Leuven Eye Study). Ophthalmic Res.. Vol. 57(2), PP.100-106, 2017.

[14]D. Snydacker, The normal optic disc. Ophthalmoscopic and photographic studies. Am J Ophthalmol . Vol. 58, PP.958-964, 1964.

[15] S. V. Kessing, E. Gregersen, The distended disc in early stages of congenital glaucoma. Acta Ophthalmol (Copenh). Jun. Vol 55(3), PP.431-5, 1977.

[16] S. S. Hayreh,Blood supply to the optic nerve and its role in optic atrophy, glaucoma and oedema of the 
optic disc. Br J Ophthalmol. Vol. 53, PP.721-748, 1969

[17]H. A. Quiglei , R. M. Hohman , E. M. Addicks, Quantitative studies ofoptic disc capillaries in chronic glaucoma in the primate and human eye. Invest Ophthalmol Vis Sci (suppi). Vol. 24, PP.102, 1984.

[18] Stuart K. Gardiner, Chris A. Johnson, Cup Size Predicts Subsequent Functional Change in Early
Glaucoma. Optom Vis Sci. 2011 Dec.vol. 88(12), PP.1470-1476, 2011.

[19] Jose Manuel Larrosa, Javier, Moreno Montanes, A diagnostic calculator for detecting glaucoma on the basis of retinal nerve fiber layer, optic disc, and retinal ganglion cell analysis by optical coherence tomography. Invest. Ophthalmol. Vis. Sci.vol. 56(11), PP.6788-6795, 2015. 